MRI safety

\section{MRI and fixed orthodontic appliances}

Sir, we were recently requested by a radiologist to remove the fixed orthodontic appliances, prior to magnetic resonance imaging (MRI) of the brain of a 15-year-old girl who sustained a traumatic brain injury in a road accident.

MRI uses magnetic fields, electric field gradients and radiowaves to produce images of the body in multiple planes. It is one of the safest medical imaging procedures currently available as it do not expose the body to harmful radiation and the images show superior soft tissue contrast to CT scans and plain films.

However, motion blur and metal artefact are significant obstacles in achieving a quality MR image.

Ferromagnetic materials, such as iron and nickel, are strongly attracted to magnets and therefore may be moved or accelerated towards the magnet and the function of some devices, such as pacemakers and hearing aids, can be affected if placed near to or within the magnetic field.

They are also known to cause large magnetic field distortions and signal loss resulting in artefact. It is widely known that all metallic removable appliances should be removed prior to MRI but metal dental filling materials do not require removal because they do not dislodge, and titanium, gold and amalgam do not reduce MR image quality of the oral and maxillofacial region. ${ }^{1}$

However, fixed orthodontic appliances are commonly made from stainless steel which has been found to cause more signal loss and image distortion compared to the less commonly used titanium and ceramic, therefore there is a general consensus that stainless steel wires should be removed before MRI to reduce the risk of image artefact, interaction with magnetic field, and possible thermal damage. ${ }^{2}$

Orthodontic brackets are considered to be 'MRI safe' but their stability should be meticulously checked and their proximity to the area of interest determined. Generally, the larger the distance between the orthodontic appliance and the area to be imaged the less image distortion, therefore the decision to remove orthodontic appliances should be based on the appliance composition and the area to be imaged. ${ }^{2}$
However, when imaging the cranium, stainless steel brackets cause significant distortion, rendering several cranial regions non-diagnostic and therefore should be removed when imaging this area. ${ }^{3}$

If the clinician cannot be sure about the type of material, all dental appliances should be treated as MRI unsafe. In this case, we did not know which orthodontic system had been fitted and therefore the material it was made from so removal of the fixed orthodontic appliances was completed prior to MRI.

Unfortunately, in the Paediatric Critical Care Unit it was not possible to remove the composite which bonded the appliance to the teeth; composites contain ferric oxide but it is considered to be an insignificant metal content which could potentially cause distortion at the tooth surface and therefore would not interfere with the image quality of an MRI brain. ${ }^{4}$

G. Stonier and P. Hardee, by email

1. Mathew C A, Maller S Maheshwaran. Interactions between magnetic resonance imaging and dental material. J Pharm Bioallied Sci 2013; 5(Suppl 1): S113-S116.

2. Poorsattar-Bejeh Mir A, Rahmati-Kamel M. Should orthodontic brackets always be removed prior to MRI? J Oral Biol Craniofacial Res 2016; 6: 142-152.

3. Elison J M, Leggitt V L, Thomson M, Oyoyo U, Wycliffe $\mathrm{ND}$. Influence of common orthodontic appliances on the diagnostic quality of cranial magnetic resonance images. Am J Orthod Dentofacial Orthop 2008: 134: 563-572.

4. Cox R J, Kau C H, Rasche V. Three-dimensional ultrashort echo magnetic resonance imaging of orthodontic appliances in the natural dentition. Am J Orthod Dentofacial Orthop 2012; 142: 552-561.

DOI: 10.1038/sj.bdj.2018.935

\section{Advertising}

\section{Giacomo Puccini in dental history}

Sir, Giacomo Puccini (1858-1924) was one of the most famous Italian opera composers, author of several renowned works, such as La bohème (1896), Tosca (1900), Madama Butterfly (1904) and Turandot (1924).

It is less known that at the beginning of the twentieth century, Puccini wrote some verses dedicated to a toothpaste.

In 1902, the German company Dresdner Chemisches Laboratorium Lingner, founded by Karl Augustus Lingner (1861-1916) in 1888, asked Puccini to advertise its new toothpaste Odol, one of the first dental products which combined cosmetic and medical effects, thanks to the addition of antiseptics.

The Italian author composed an ode to the toothpaste, using numerous plays on words around the brand's name.
The verses were published in the Italian journal Rivista Italiana in June of the same year, contributing to the success of the product, but also to the diffusion of the utilisation of toothpaste among Italians.

In conclusion, at the beginning of the last century, the internationally renowned figure of Giacomo Puccini played an important and often-forgotten role in the development of oral hygiene, and, therefore, in dental history.

\section{A. Riva, School of Medicine and Surgery, University of Milano Bicocca DOI: 10.1038/sj.bdj.2018.936}

\section{CBCT scans}

\section{Teleradiology services}

Sir, CBCT scans are increasing in prevalence and there has been a longstanding request from practitioners as to the provision of specialist radiology reports.

As readers will be aware, all radiographic images are required by law to be evaluated (reported) according to IRMER. Nonspecialist radiologists may report scans themselves, many having attended a CBCT reporting course; however, practitioners may also wish to have scans reported (or give a second opinion) by a specialist.

GDC registered specialists/consultants in dental radiology are mainly limited to larger dental hospitals so it is likely they will be in a different physical location. This practice is called teleradiology and has been present in medical radiology for several years already.

In a Royal College of Radiology (RCR) census from 2009, teleradiology was present in nearly $40 \%$ of hospitals. ${ }^{1}$

The RCR have written guidelines ${ }^{2}$ on the provision of teleradiology for medicine and in the absence of dental specific guidance, these guidelines can be extrapolated to dentistry.

The RCR has produced standards for teleradiology but there are two particular standards which dental practitioners should be aware of.

One strand says: 'There should be clear and transparent systems in place for rapid, secure transfer and review of images and, where necessary, storage of patient data.'

A secure data transfer service should be used, such as 256-bit encryption. Non encrypted images on CDs/USB keys sent in the post are unlikely to satisfy this requirement. 
The other strand says: 'Teleradiologists reporting imaging of British patients should be registered on the General Medical Council (GMC) Clinical Radiology Specialist Register and indemnified to the same standards as those of the base healthcare organisation.'

This can be extrapolated into dentistry that teleradiology services for CBCT reporting should only be prepared by GDC registered specialists in dental and maxillofacial radiology or GMC registered specialist (head and neck) radiologists.

Reports prepared by practitioners outside the UK who are not registered with the GDC (even if they are registered with their own national body) are unlikely to satisfy this criteria and potentially leave the patient and clinician vulnerable.

\section{S. Harvey, by email}

1. The Royal College of Radiologists. Teleradiology and outsourcing census. London: The Royal College of Radiologists, 2010. Ref No. BFCR(10)8. Available at https://www.rcr.ac.uk/publication/teleradiology-and-outsourcing-census (accessed 9 October 2018).

2. The Royal College of Radiologists. Standards for the provision of teleradiology within the United Kingdom, second edition. London: The Royal College of Radiologists, 2016. Ref No. BFCR(16)8. Available at https://www. rcr.ac.uk/publication/standards-provision-teleradiology-within-united-kingdom-second-edition (accessed 9 October 2018)

\section{DOI: $10.1038 /$ sj.bdj.2018.937}

\section{Patient safety}

\section{Never say never}

Sir, we read the opinion article by Dr Barclay regarding 'Never Events' with interest.

In view of the comments in the final paragraph it is worth pointing out that this has been an issue of interest to the Association of Dental Hospitals (ADH) for several years, including as shown in work published in this Journal. ${ }^{2}$

In the English NHS, 'Never Events' were initially introduced in 2009, with 'wrong tooth extraction' being explicitly identified in the 2012 revision. Since then, this has been found to be the most frequent wrong site surgery 'Never Event' reported with most of the reports emanating from hospitals and community services, so clearly dentistry has room to improve on issues of patient safety. ${ }^{3,4}$

In 2016, NHSI went out to consultation on the Never Events policy and framework and in its submission the ADH made several of the points raised by Dr Barclay.

NHSI of course ultimately decides which views it wishes to follow and the resulting new guidance, to which Dr Barclay refers, was only released in late January of this year (2018) for implementation shortly thereafter at the start of February.

Since then, several ADH member hospitals have raised concerns such that in October 2018, an ADH meeting has been arranged to discuss our individual interpretations of the current guidance with the aim of forming a consensus $\mathrm{ADH}$ view.

M. N. Pemberton, immediate past Chair of $A D H$, Manchester and A. Macpherson, current Chair of ADH, Liverpool

1. Barclay S C. Is it the world or is it me? Br Dent J 2018; 225: 117-118. Available at https://www.nature.com/ articles/sj.bdj.2018.533 (accessed 9 October 2018).

2. Pemberton M N. Surgical safety checklists and understanding of Never Events in UK and Irish Dental hospitals. Br Dent J 2016; 220: 585-589. Available at https:// www.nature.com/articles/sj.bdj.2016.414 (accessed 9 October 2018).

3. Pemberton M N, Ashley M P, Saksena A, Dickson S. Wrong tooth extraction: an examination of 'Never Event' data. Br J Oral Maxillofac Surg 2017; 55: 187-188.

4. Cullingham P, Saksena A, Pemberton M N. Patient safety: reducing the risk of wrong tooth extraction. Br Dent J 2017; 222: 759-763. Available at https:// www.nature.com/articles/sj.bdj.2017.448 (accessed on 9 October 2018).

DOI: $10.1038 /$ sj.bdj.2018.938

\section{Child capacity and protection}

\section{Gillick research needed}

Sir, 1984 saw a landmark legal ruling on the issue of child capacity - Gillick v West Norfolk and Wisbech Area Health Authority and Department of Health and Social Security.

This, in essence, was subsequently upheld by the House of Lords in 1985 with Lord Scarman's test which is generally considered to be that which defines 'Gillick competency'

It said: 'As a matter of Law the parental right to determine whether or not their minor child below the age of 16 will have medical treatment terminates if and when the child achieves sufficient understanding and intelligence to understand fully what is proposed.'

This decision had profound implications for the provision of all healthcare services, including dental care, to children under 16 years old. Its importance is reflected in the clear, concise public statements on Gillick competency (and consent in relation to 16- and 17-year-olds) provided by the Department of Health (NHS Choices) ${ }^{1}$ and the CQC. ${ }^{2}$

Evidence of the profession's regard for and concern with child protection in general and children's capacity to make decisions relating to their dental care is to be found in the dental discussion forum, https://www.gdpuk.com/.

Since 2008 and as at the time of writing, there were 367 posts which included the keywords 'child' and 'protection', nearly 200 posts which include 'child' and 'consent', and over 50 which included the term 'Gillick'.

Additionally, a short survey (poll) on the subject was posted on https://www.gdpuk. $\mathrm{com} /$ and ran for seven days and asked what percentages ( $[<25 \%],[25 \%$ to $<50 \%]$, [ $50 \%$ to $<75 \%$ ] and [75\% to $100 \%]$ ) of patients they believe are Gillick competent among 12-13year-olds and 14-15-year-olds.

A third question asked if members believe girls generally achieve Gillick Competency before boys or at the same age as boys.

The results indicated that the belief that $51 \%(n=23)$ of $12-13$-year-olds and $69 \%$ $(\mathrm{n}=27)$ of $14-15$-year-olds have capacity to consent to general dental treatment.

Also, $69 \%(n=26)$ believe girls generally achieve Gillick competency before boys.

Although limited in extent, the poll strongly suggests that GDPs view a large proportion of 12-15-year-olds as being Gillick competent and that they consider gender to be a factor which influences that capacity.

Despite the strong engagement of the profession with this issue and the findings reported above, the apparent paucity of other Gillick-competency-related research does suggest there are deficits in our knowledge in this field of dental ethics. The authors hope that this letter will spur more formal research Gillick competence across the relevant age range.

P. V. McCrory and A. V. Jacobs, by email

1. Department of Health. Children and young people - Consent to treatment (2016). Available at https:// www.nhs.uk/conditions/consent-to-treatment/children/ (accessed 9 October 2018).

2. Care Quality Commission. Nigel's surgery 8: Gillick competency and Fraser guidelines (2018). Available at https://www.cqc.org.uk/guidance-providers/gps/ nigels-surgery-8-gillick-competency-fraser-guidelines. (accessed 9 October 2018).

DOI: $10.1038 /$ sj.bdj.2018.939

\section{Tobacco control}

\section{Safer without snus}

Sir, I was alarmed to see that a recent report on e-cigarettes, by the Science and Technology Committee (17 August 2018), suggested a review on the 'discontinuation' of the ban on snus after Brexit.

Snus is a smokeless snuff tobacco, typically placed under the lip. It is carcinogenic and was banned throughout the EU in 1992. 